\title{
Ocorrência da infecção por Cryptosporidium spp. em cabritos (Capra hircus) $^{1}$
}

\begin{abstract}
Roberta Lomonte Lemos de Brito ${ }^{2 *}$, Sandra Valéria Inácioº ${ }^{3}$ Dalilian Antoniete dos Santos Oliveira ${ }^{4}$, Maximiana Mesquita de Sousa ${ }^{4}$, Marcelo Vasconcelos Meireles ${ }^{3}$, Raimundo Nonato Braga Lobo ${ }^{5}$, Luiz da Silva Vieira ${ }^{5}$ e Katia Denise Saraiva Bresciani ${ }^{3}$

ABSTRACT.- Brito R.L.L., Inácio S.V., Oliveira D.A.S., Sousa M.M., Meireles M.V., Lobo R.N.B., Vieira L.S. \& Bresciani K.D.S. 2014. [Occurrence of infection by Cryptosporidium spp. in goat kids (Capra hircus).] Ocorrência da infecção por Cryptosporidium spp. em cabritos (Capra hircus). Pesquisa Veterinária Brasileira 34(8):728-732. Programa de Pós-Graduação em Medicina Veterinária, Faculdade de Ciências Agrárias e Veterinária, Universidade Estadual Paulista, Via de Acesso Prof. Paulo Donato Castellane s/n, Jaboticabal, SP 14884-900, Brazil. E-mail: rolomonte@gmail.com

The present study aimed to determine the occurrence of infection by Cryptosporidium spp. in goat kids from Quixadá, Ceará, Brazil. The study included 400 goat kids of both sexes, 3 to 360 days old, with or without defined breed, originating from 25 farms distributed in three circuits. Feces were registered in accordance with the appearance and color, distributed into tubes Eppendorf tubes and frozen in natura at $-20^{\circ} \mathrm{C}$ until the moment of extraction of genomic DNA from the parasite with the aid of a commercial kit. For amplification of fragments of the 18S subunit of ribosomal RNA (rRNA) was used to Nested PCR. The occurrence of Cryptosporidium spp. in goats kids of the Quixadá was 7.50\% (30/400). The frequency in the dry period and rainy was 9.55\% (19/199) and 5.47\% (11/201) respectively $\left(\chi^{2}=2.39\right.$ and $\left.P>0.05\right)$. Positive samples were identified in $64.00 \%(16 / 25)$ of the studied farms, and from these samples $50.00 \%(15 / 30)$ and $70.00 \%(21 / 30)$ had feces with normal appearance and color respectively, suggesting that the asymptomatic goats were eliminating oocysts. No positivity for Cryptosporidium spp. was observed in 301 to 360-day-old goats, demonstrating that older animals have less chance to become infected with the parasite.
\end{abstract}

INDEX TERMS:Goats, age, asymptomatic, Cryptosporidium spp., diarrhea, dry period, Nested-PCR.

RESUMO.- 0 presente estudo teve como objetivo determinar a ocorrência da infecção por Cryptosporidium spp. em cabritos de Quixadá, Ceará, Brasil. Participaram do estudo 400 cabritos, com idade entre três e 360 dias, de ambos os

\footnotetext{
${ }^{1}$ Recebido em 30 de janeiro de 2014.

Aceito para publicação em 4 de junho de 2014.

${ }^{2}$ Programa de Pós-Graduação em Medicina Veterinária, Faculdade de Ciências Agrárias e Veterinárias (FCAV), Universidade Estadual Paulista (Unesp), Via de Acesso Prof. Paulo Donato Castellane s/n, Jaboticabal, SP 14884-900, Brasil. Bolsista da Fundação de Amparo à Pesquisa do Estado de São Paulo (FAPESP).*Autor para correspondência: rolomonte@gmail.com

${ }^{3}$ Faculdade de Medicina Veterinária de Araçatuba (FMVA) Unesp, Rua Clóvis Pestana 793, Araçatuba, SP 16050-680, Brasil.

${ }^{4}$ Universidade Estadual Vale do Acaraú (UVA), Centro de Ciências Agrárias e Biológicas, Avenida da Universidade 850, Campus da Betânia, Sobral, CE 62040-370, Brasil.

${ }^{5}$ Embrapa Caprinos e Ovinos, Estrada Sobral/Groaíras Km 4, Zona Rural, Cx. Postal 145, Sobral, CE 62011-970, Brasil.
}

sexos, com e sem padrão racial definido, procedentes de 25 estabelecimentos rurais distribuídos em três circuitos. As fezes foram cadastradas de acordo com o aspecto e cor, distribuídas em tubos tipo "eppendorf ${ }^{\circledR}$ " e congeladas in natura a $-20^{\circ} \mathrm{C}$, até o momento das extrações de DNA genômico do parasito com auxílio de kit comercial. Para amplificação de fragmentos da subunidade $18 \mathrm{~S}$ do RNA ribossômico (rRNA) foi utilizada a "Nested"-PCR. A ocorrência de Cryptosporidium spp em cabritos de Quixadá foi de 7,50\% (30/400). A frequência no período seco e no chuvoso foi de $9,55 \%(19 / 199)$ e $5,47 \%(11 / 201)$, respectivamente $\left(\chi^{2}=2,39\right.$ e $\left.P>0,05\right)$. Amostras positivas foram identificadas em $64,00 \%(16 / 25)$ das propriedades estudadas e dessas amostras $50,00 \%(15 / 30)$ e $70,00 \%(21 / 30)$ tinham as fezes com aspecto e cor normais, respectivamente, sugerindo que cabritos assintomáticos estão eliminando oocistos. Não foi observada positividade para Cryptosporidium spp. 
em animais com 301 a 360 dias, demonstrando que animais mais velhos apresentam menos possibilidade de se infectarem com o parasito.

TERMOS DE INDEXAÇÃO: Caprinos, Idade, assintomático, Cryptosporidium spp. diarreia, período seco, Nested-PCR.

\section{INTRODUÇÃO}

A criptosporidiose tem emergido como causa significante de perdas econômicas diretas e indiretas na caprinocultura, por comprometer o desenvolvimento e a produção de caprinos, visto que há redução no ganho de peso vivo e na produção leiteira dos animais acometidos, especialmente quando são mantidos em sistema de criação com falhas no manejo sanitário e nutricional (Vieira et al. 1997, Zorana et al. 2006, Soltane et al. 2007).

A primeira descrição de protozoários pertencentes ao gênero Cryptosporidium ocorreu em 1907 por Tyzzer em camundongo de laboratório. Em cabritos a primeira evidência ocorreu na Austrália (Mason et al. 1981) e no Brasil foi registrada em 1997 por Vieira e colaboradores. Esses coccídios apresentam distribuição cosmopolita e desde essas descrições, diversas espécies do coccídio vêm sendo identificadas nos mais diferentes tipos de hospedeiros vertebrados.

Pesquisas em diferentes regiões do planeta revelam que a ocorrência da infecção por Cryptosporidium spp. em caprinos varia entre: $5 \%<$ e $>35 \%$, com média de $15 \%$ (Robertson 2009). Com 0,0\% na Polônia (Majewska et al. 2000); de 0,0 a 20,0\% na França, com uma frequência individual de 2,5\% (Castro-Hermida et al. 2005, Delafosse et al. 2006); 4,8\% no Zâmbia (Goma et al. 2007); 9,0\% na Espanha (Castro-Hermida et al. 2007); 9,5\% na Bélgica (Geurden et al. 2008); 24,0\% na Nigéria (Pam et al. 2013); $28,5 \%$ na Sri Lanka (Noordeen et al. 2000); 31,8\% na Sérvia (Zorana et al. 2006) e 67,7\% na Argentina (Venturini et al. 2006). Sendo associados a baixas ocorrências em sistemas de produção extensivo (Tembue et al. 2006) e altas em sistemas de confinamento/intensivos (Causapé et al. 2002, Bomfim et al. 2005, Cosendey et al. 2008).

Causam enfermidade com carácter oportunista, podendo ser observado $100 \%$ de morbidade e $50 \%$ de mortalidade em diferentes rebanhos (Fayer 2004, Santín 2013), com uma frequência maior em caprinos com menos de cinco meses de vida (Noordeen et al. 2001). Com o avançar da idade, se tornam resistentes contra a infecção por conta da produção de anticorpos, que possuem ação duradoura e são capazes de bloquear os esporozoítos (Moss et al. 2004, Johnson et al. 2004).

A gravidade do parasitismo por Cryptosporidium spp. depende principalmente da carga parasitária, da idade e estado imunológico do hospedeiro (Silva et al. 1999, Noordeen et al. 2002, Bomfim et al. 2005, Pavlovic et al. 2010), sendo mais severa em jovens e imunossuprimidos (Vieira et al. 1997, De Graff et al. 1999). A manifestação clínica pode variar de assintomática a grave, que ocasionalmente culmina em óbito. A sintomatologia mais comum é a diarreia e coincide com o período de maior eliminação dos oocistos (Noordeen et al. 2002).
A diarreia é ocasionada por conta do ciclo de vida do parasito, visto que se localizam de forma intracelular e extracitoplasmática no ápice das vilosidades das células intestinais de seus hospedeiros vertebrados (Tzipori \& Griffths 1998, Xiao et al. 2004), levando a destruição e atrofia das mesmas, proporcionando redução na absorção e digestão dos nutrientes (Vieira et al. 1997, Soltane et al. 2007, Paraud \& Chartier 2012).

Os adultos normalmente não apresentam sintomatologia e podem eliminar oocistos, servindo como reservatório para cabritos (Noordeen et al. 2000, Noordeen et al. 2002, Santín 2013). A principal via de transmissão é a oral, por meio da ingestão dos oocistos esporulados ou lambedura de material contaminado com estas estruturas parasitárias (Paraud \& Chartier 2012).

Muitas ferramentas têm sido empregadas no diagnóstico da criptosporidiose, como a microscopia com contraste de fase usando solução de Sheather (Garcia et al. 1983, Feitosa et al. 2008, Teixeira et al. 2011), coloração com fucsina-carbólica no Ziehl-Neelsen modificado (Henriksen \& Pohlenz 1981) ou no Kinyoun (Zorana et al. 2006), reação de imunofluorescência direta (Zimmerman \& Needham 1995, Bialek et al. 2002, Teixeira et al. 2011), testes comerciais imunoenzimáticos (ELISA) e reação em cadeia da polimerase (PCR).

Estudos sobre a presença do parasito em rebanhos nacionais são escassos, principalmente na região Nordeste, relevando a necessidade de projetos de pesquisa que dão enfoque ao assunto. Diante disto, este estudo teve como objetivo determinar a ocorrência da infecção por Cryptosporidium spp em cabritos de Quixadá, Ceará, Brasil.

\section{MATERIAL E MÉTODOS}

O estudo foi realizado no município de Quixadá, localizado na região semiárida dos Sertões cearenses. Tem o clima caracterizado por um período chuvoso de janeiro a junho e um seco de julho a dezembro. A pluviosidade média é de $838,1 \mathrm{~mm} / \mathrm{ano}$, com temperatura elevada ao longo do ano, tendo média de $26,7^{\circ} \mathrm{C}$ e umidade relativa do ar de $70 \%$.

0 rebanho caprino avaliado era composto por 9750 animais distribuídos em 469 propriedades, o que representa $0,96 \%$ do rebanho cearense (Ibge 2014). Para obtenção do número amostral, foi adotada uma distribuição normal, com 5\% de significância, considerando-se o intervalo de confiança de $95 \%$ e prevalência estimada de $50 \%$, pois não era conhecida a ocorrência da enfermidade na região.

As coletas de fezes foram realizadas no período de novembro a dezembro de 2012, caracterizando a estação seca, com precipitação pluviométrica média de $0,0 \mathrm{~mm}$ e em maio de 2013 , que corresponde a estação chuvosa, com uma média de 150,7mm entre abril e maio de 2013 (Fuceme 2014). Participaram do estudo 400 cabritos, com idade entre três e 360 dias, de ambos os sexos, com padrão racial definido (CPRD) e sem padrão racial definido (SPRD), procedentes de 25 estabelecimentos rurais distribuídos em três circuitos (C1, C2 e C3). Nas duas estações do ano foram realizadas visitas as mesmas propriedades.

Para escolha dos proprietários optou-se por sorteio aleatório a partir de informações fornecidas pela Empresa de Assistência Técnica e Extensão Rural do Ceará, unidade de Quixadá. Desta forma, o circuito um (C1) englobou os distritos: Califórnia ( $\mathrm{n}=5$ propriedades), Daniel de Queiroz ( $n=1)$ e São João dos Queirozes $(n=3)$, correspondendo a $36 \%$ das propriedades. 0 circuito dois (C2): Cipó dos Anjos ( $n=6)$ e Tapuiará $(n=2)$ e o circuito três (C3): 
Juatama $(n=1)$, Riacho Verde $(n=1)$, Novo Contrato $(n=1)$ e Sede $(n=5)$, cada um equivalendo a $32 \%$ dos estabelecimentos rurais.

As fezes foram obtidas diretamente da ampola retal dos cabritos, armazenadas em saco plástico individual devidamente identificado e refrigeradas até o momento em que foram cadastradas de acordo com o aspecto e cor. Posteriormente foram distribuídas em tubos tipo "eppendorf ${ }^{\circledR}$ ", sendo congeladas in natura a $-20^{\circ} \mathrm{C}$. Para o aspecto foi adotado: grude (A1); cibalas (A2); diarreia (A3); amolecida (A4) e ressecada (A5) e para cor: normal (V1); verde (V2); verde amarelado (V3); amarelado (V4) e marrom com muco laranja (V5).

Foram realizadas extrações de DNA genômico de Cryptosporidium spp. das amostras de fezes com auxílio do "QIAamp DNA Stool Mini Kit (50)", Cat. № 51504 (Qiagen ${ }^{\circledR}$ ), seguido o protocolo descrito pelo fabricante. Para amplificação de fragmentos da subunidade 18S do RNA ribossômico (rRNA) na "Nested"-PCR, foi utilizada metodologia descrita por Xiao et al. (2000), utilizando os primers 5' TTC TAG AGC TAA TAC ATG CG 3' e 5' CCC ATT TCC TTC GAA ACA GGA 3' de 1325 pares de base (pb) na reação primária e 5' GGA AGG GTT GTA TTT ATT AGA TAA AG 3' e 5' AAG GAG TAA GGA ACA ACC TCC A 3' na reação secundária (826-840 pb).

As análises estatísticas foram realizadas no PROC FREQ e GLM do SAS (Sas Institute 1996) e efetuada em dois momentos. No primeiro cada variável independente (período seco e chuvoso; circuitos; idade; sexo; raça; aspecto e cor das fezes) foi cruzada com a variável dependente (Positividade para Cryptosporidium spp. na "Nested"-PCR) em uma análise univariada. Foram selecionadas aquelas significativas e submetidas à análise multivariada (Zar 1999). Nesta utilizou-se a regressão logística com nível de 5\% de significância.

O estudo teve aprovação na Comissão de Ética no Uso de Animais da Faculdade de Ciências Agrárias e Veterinárias da Universidade Estadual Paulista-"Júlio de Mesquita Filho", Jaboticabal, SP, com o Protocolo no 014465/12.

\section{RESULTADOS}

Das 400 amostras de fezes submetidas ao "Nested"-PCR, 30 tiveram amplificação do gene da subunidade 18S do rRNA de Cryptosporidium spp., o que corresponde a uma ocorrência de 7,50\%. Quando os períodos foram comparados, observou-se que a frequência na estação seca e na chuvosa, foi de $9,55 \%$ (19/199) e 5,47\% (11/201), respectivamente $\left(\chi^{2}=2,39\right.$ e $\left.\mathrm{P}>0,05\right)$.

Os animais foram separados em faixa etária (FE), sendo que 19,75\% (79/400) tinham entre 3 e 60 dias de vida (FE1); $30 \%(120 / 400)$ de 61-120 dias (FE2); 30\% (120/400) de 121-180 (FE3); $12 \%$ (48/400) de 181-240 (FE4); 5\% (20/400) de 241-300 (FE5) e 3,25\% (13/400) de 301-360 dias agrupados na FE seis $\left(\chi^{2}=61,12\right.$ e $\left.\mathrm{P}<0,05\right)$. Dos cabritos positivos para Cryptosporidium spp. na "Nested"-PCR 10\% (24/240) tinham idade de 61-180 dias, o que corresponde a $80,00 \%(24 / 30)$ de positividade e nenhum com 301-360 dias de vida foi positivo $\left(\chi^{2}=10,83\right.$ e $\left.\mathrm{P}>0,05\right)$.

Com relação ao sexo, 61,50\% (246/400) eram fêmeas e 7,72\% (19/246) foram positivas na "Nested-PCR". Os machos corresponderam a 38,50\% (154/400) e 7,14\% $(11 / 154)$ foram positivos $\left(\chi^{2}=0,05\right.$ e $\left.P>0,05\right)$.

Dos cabritos estudados, 79,00\% (316/400) era sem padrão racial definido e 7,59\% (24/316) destes foram positivos. Os 21,00\% (84/400) eram CPRD e seis tiveram amplificação do gene da subunidade $18 \mathrm{~S}$ do rRNA de Cryptosporidium spp. o que equivale a uma frequência de $7,14 \%$ $\left(\chi^{2}=0,02\right.$ e $\left.P>0,05\right)$.
Amostras positivas para Cryptosporidium spp. foram identificadas em 64\% (16/25) das propriedades estudadas. Quando estas foram separadas em circuitos, foi observado que no $\mathrm{C} 1$ a frequência de estabelecimentos rurais positivos foi de $66,67 \%$ (6/9) e tanto no C2 como no C3 cinco de oito criações tiveram animais positivos, o que corresponde $62,50 \%$ de positividade em cada um desses dois circuitos $\left(\chi^{2}=0,63\right.$ e $\left.P>0,05\right)$.

Foi observado que 51,75\% (207/400) das amostras apresentavam aspecto normal, ou seja, estavam na forma de cíbalas e 73,75\% (295/400) tinham cor normal. Nenhuma amostra diarreica ou com aspecto grude foram positivas (P>0,05) para Cryptosporidium spp. (Quadro1).

Das amostras positivas 90,00\% tinham coloração V1, V4 e V5 (Quadro 2). Além disso, 50,00\% (15/30) e 70,00\% (21/30) das amostras positivas para o parasito tinham aspecto e cor normais (V1), respectivamente.

$\mathrm{Na}$ análise de regressão logística, apenas idade $\left(4 \mathrm{gl}, \chi^{2}=\right.$ $13,54$ e $\mathrm{P}<0,05)$ e cor $\left(4 \mathrm{gl}, \chi^{2}=18,09\right.$ e $\left.\mathrm{P}<0,05\right)$ foram significativos (Quadro 3).

Quadro 1. Frequência de Cryptosporidium sp. observada em amostras de fezes de $\mathbf{4 0 0}$ cabritos provenientes de 25 propriedades rurais de Quixadá, Ceará, com relação ao aspecto utilizando a "Nested"-PCR

\begin{tabular}{|c|c|c|c|c|c|}
\hline \multirow[t]{2}{*}{ “Nested”-PCR } & \multicolumn{5}{|c|}{ Aspecto } \\
\hline & Grude & Cíbalas & Diarreia & Amolecida & Ressecada \\
\hline Positivo & $0(0,00 \%)$ & $15(3,75 \%)$ & $0(0,00 \%)$ & $9(2,25 \%)$ & $6(1,50 \%)$ \\
\hline Negativo & $4(1,00 \%)$ & $192(48,00 \%)$ & $7(1,75 \%)$ & $75(18,75 \%)$ & $92(23,00 \%)$ \\
\hline
\end{tabular}

Quadro 2. Frequência de Cryptosporidium sp. observada em amostras de fezes de 400 cabritos provenientes de 25 propriedades rurais de Quixadá, Ceará, com relação a cor utilizando a "Nested"-PCR

\begin{tabular}{cccccc}
\hline \multirow{2}{*}{ "Nested"-PCR } & \multicolumn{5}{c}{ Cor* } \\
\cline { 2 - 6 } & V1 & V2 & V3 & V4 & V5 \\
\hline Positivo & $21(5,25 \%)$ & $2(0,50 \%)$ & $1(0,25 \%)$ & $3(0,75 \%)$ & $3(0,75 \%)$ \\
Negativo & $274(68,50 \%)$ & $37(9,25 \%)$ & $24(6,00 \%)$ & $26(6,50 \%)$ & $9(2,25 \%)$
\end{tabular}

* V1 = normal, V2 = verde, V3 = verde amarelado, V4 = amarelado e V5 = marrom com muco laranja. $\chi 2$ - (4gl) $6,45(\mathrm{P}>0,05)$.

Quadro 3. Faixa etária dos cabritos de Quixadá, Ceará e cor de suas fezes

\begin{tabular}{lcccc}
\hline \multicolumn{1}{c}{ Efeito } & $\begin{array}{c}\text { Chances } \\
\text { de ocorrer }\end{array}$ & \multicolumn{2}{c}{$\begin{array}{c}\text { Intervalo de confiança } \\
\text { de Wald (95\%) }\end{array}$} & $\begin{array}{c}\text { Contraste } \\
\chi^{2} \text { de Wald }\end{array}$ \\
\cline { 3 - 4 } & & $\begin{array}{c}\text { Limite } \\
\text { inferior }\end{array}$ & $\begin{array}{c}\text { Limite } \\
\text { Superior }\end{array}$ & \\
\hline FE1 x FE5a & 0,05 & 0,01 & 0,36 & $8,83^{* *}$ \\
FE2 x FE5a & 0,81 & 0,16 & 4,04 & $0,06^{\text {ns }}$ \\
FE3 x FE5a & 1,96 & 0,44 & 8,78 & $0,77^{\text {ns }}$ \\
FE4 x FE5a & 0,21 & 0,02 & 2,26 & $1,67^{\text {ns }}$ \\
Cor (V1 x V5) & 0,02 & 0,003 & 0,13 & $16,28^{* *}$ \\
Cor (V2 x V5) & 0,01 & 0,001 & 0,09 & $14,46^{* *}$ \\
Cor (V3 x V5) & 0,01 & 0,001 & 0,21 & $9,26^{* *}$ \\
Cor (V4 x V5) & 0,05 & 0,01 & 0,34 & $9,35^{* *}$
\end{tabular}

Faixa etária: FE1 = 3 e 60 dias de vida, FE2 = 61 a 120 dias, FE3 = 121 a 180 dias, FE4 = 181 a 240 dias e FE5a = 241 a 360 dias. Cor: V1 = normal, V2 = verde, V3 = verde amarelado, V4 = amarelado e V5 = marrom com muco laranja. ${ }^{\mathrm{ns}} \mathrm{P}>0,05 \mathrm{e}^{* *} \mathrm{P}<0,05$. 


\section{DISCUSSÃO}

A ocorrência encontrada em Quixadá, Ceará de 7,50\% está próxima a encontrada em estudos na região Sudeste do Brasil que varia de $4,8 \%$ (Bomfim et al. 2005) a $16,66 \%$ (Coelho 2011). A maior frequência do parasitismo por Cryptosporidium spp na estação seca também foi relatada por Noordeen et al. (2000) e Noordeen et al. (2001) na Sri Lanka, ressaltando a resistência que o coccídio tem as condições adversas do meio ambiente, podendo sobreviver fora do animal por um longo período de tempo (Pavlovic et al. 2010) e infectar animais em qualquer época do ano. Vale salientar que a precipitação pluviométrica média em Quixadá nesse período foi de $0,0 \mathrm{~mm}$.

Em épocas de seca existe escassez de alimento, sendo um problema maior para animais que são criados em sistema extensivos sem nenhuma suplementação alimentar (Noordeen et al. 2000). Isto de certa forma pode ocasionar estresse (Goma et al. 2007), além de comprometer a aquisição de nutrientes que entrarão na composição de várias biomoléculas, inclusive imunoglobulinas. Aliado a isto, nesse período os animais passam mais tempo presos, defecando no cocho e nas instalações, contaminando o meio ambiente o que pode facilitar a transmissão.

A elevada ocorrência de amostras positivas para Cryptosporidium spp. nas propriedades estudadas, corrobora com Geurden et al. (2008) e Noordeen et al. (2000), que encontraram $60 \%$ e $96 \%$ de positividade nas fazendas, respectivamente. Demonstrando que formas infectantes do parasito encontram-se disseminadas, além disso, isso pode ter ocorrido porque em Quixadá, Ceará, os produtores costumam vender os animais em feiras livres na Sede do município, o que pode ter facilitado o transporte de animais infectados de uma propriedade para outra.

Com relação à idade, em pesquisas realizadas por Zorana et al. (2006) observaram maior frequência de infecção em cabritos com um a 30 dias de idade e de Pavlovic et al. (2010) com cinco a 21 dias de idade. Segundo Noordeen et al. (2001) e Bomfim et al. (2005), a faixa etária mais susceptível à infecção por Cryptosporidium spp. é de animais com menos de 150 dias e coincide com o período de maior eliminação de oocistos e de fezes com aspecto diarreico (Castro-Hermida et al. 2005) e coloração amarelada a marrom-amarelada (Mason et al. 1981).

Esses achados discordam com o presente estudo onde nenhum cabrito do município de Quixadá com diarreia foi positivo para o protozoário e a FE mais acometida foi de 121-180 dias, isso provavelmente ocorreu porque em muitas propriedades os animais eram submetidos a manejos que poderiam causar estresse, como desmama e cobertura.

Além disso, a susceptibilidade diminui com o avançar da idade fato esse observado nos cabritos com idade entre 241 e 360 dias, que foram negativos para infecção pelo protozoário. Isso ocorre por conta da produção de anticorpos que apresentam ação duradoura e são capazes de bloquear os esporozoítos na superfície dos enterócitos, levando a resistência contra infecção (Johnson et al. 2004, Moss et al. 2004), provavelmente isso pode ter contribuído para que os animais de Quixadá, Ceará, não apresentassem diarreia.

Com relação ao sexo, a maior frequência de fêmeas positivas também foi observado por Pam et al. (2013) na Nigéria e das amostras positivas para o parasito, $50,00 \%$ tinham aspecto de cíbalas e 70,00\% tinham coloração normal, evidenciando que a ocorrência em cabritos assintomáticos pode ser alta, corroborando com Noordeen et al. (2000) e Castro-Hermida et al. (2007). Isso provavelmente ocorreu porque os animais mais acometidos tinham idade entre 121 e 180 dias, nessa fase os cabritos são mais imunocompetentes e a produção de anticorpos apresenta ação duradoura contra o coccídio (Moss et al. 2004, Johnson et al. 2004), reduzindo a manifestação dos sinais clínicos.

0 presente estudo é o primeiro que evidencia a ocorrência da infecção por Cryptosporidium spp em caprinos no Nordeste brasileiro, utilizando como diagnóstico a Nested-PCR com gene 18S rRNA. Formas infectantes do parasito estão presentes em propriedades de Quixadá, Ceará e a casuística foi maior em animais assintomáticos, demonstrando a importância desses como reservatórios para outros hospedeiros.

Agradecimentos.- À Universidade Estadual Paulista "Júlio de Mesquita Filho" (FCAV-Unesp), em Jaboticabal/SP, à Fundação de Amparo à Pesquisa do Estado de São Paulo (FAPESP), À Empresa Brasileira de Pesquisa Agropecuária (Embrapa), à Universidade Estadual Vale do Acaraú (UVA à Fundação Cearense de Apoio ao Desenvolvimento Científico e Tecnológico (Funcap) e à Empresa de Assistência Técnica e Extensão Rural do Ceará (EMATERCE) Unidade de Quixadá/CE.

\section{REFERÊNCIAS}

Bialek R., Binder N., Dietz K., Joachim A., Knobloch J. \& Zelck U. 2002. Comparison of fluorescence, antigen and PCR assays to detect Cryptosporidium parvum in fecal specimens. Diagn. Microbiol. Infect. Dis. 43:283-288.

Bomfim T.C.B., Huber F., Gomes R.S. \& Alves L.L. 2005. Natural infection by Giardia sp. and Cryptosporidium sp. in dairy goats, associated with possible risk factors of the studied properties. Vet. Parasitol. 134:9-13.

Castro-Hermida J.A., Gonzáles-Warleta M. \& Mezo M. 2007. Natural infection by Cryptosporidium parvum and Giardia duodenalis in sheep and goats in Galicia (NW Spain). Small Rum. Res. 72:96-100.

Castro-Hermida J.A., Pors I., Poupin B., Ares-Mazás E. \& Chartier C. 2005. Prevalence of Giardia duodenalis and Cryptosporidium parvum in goat kids in western France. Small Rum. Res.56:259-264.

Causapé A.C., Quílez J., Sánchez-acedo C., Del Cacho E. \& López-Bernad F. 2002. Prevalence and analysis of potential risk factors for Cryptosporidium parvum infection in lambs in Zaragoza (northeastern Spain). Vet. Parasitol. 104:475-486.

Coelho W.M.D. 2011. Detecção molecular e subtipagem de Cryptosporidium spp. em caprinos, ovinos, bovinos, leitões e equinos jovens. Tese em Medicina Veterinária Preventiva, Universidade Estadual Paulista "Júlio de Mesquita Filho", Jaboticabal, SP. 84p.

Cosendey R.I.J., Fiuza V.R.S. \& Oliveira F.C.R. 2008. Importância do manejo na criptosporidiose em criações de ovinos. Revta Bras. Parasitol. Vet. 17:209-214

De Graaf D.C., Vanopdenbosh E., Ortega-Mora L.M., Abbassi H. \& Peeters J.E. 1999. A review of the cryptosporidiosis in farm animals. Aust. Soc. Parasitol. 29:1269-1287.

Delafosse A., Castro-Hermida J.A., Baudry C., Ares-Mazás E. \& Chartier C. 2006. Herd-level risk factors for Cryptosporidium infection in dairy-goat kids in western France. Prev. Vet. Med.77:109-121.

Fayer R. 2004. Cryptosporidium: a water-borne zoonotic parasite. Vet. Parasitol. 126:37-56.

Feitosa F.L.F., Shimamura G.M., Mendes L.C.N., Peiró J.R., Féres F.C., Bovino F., Perri S.H.V. \& Meireles M.V. 2008. Importância de Cryptosporidium spp. como causa de diarréia em bezerros. Pesq. Vet. Bras. 28:452-456. 
Fuceme 2014. Fundação Cearense de Meteorologia e Recursos Hídricos. Séries Históricas: Pluviometria Anual (mm) de Quixadá, Ceará, Brasil. Disponível em <http://www.funceme.br/produtos/script/chuvas/ Download_de_series_historicas/downloadHistoricos/postos/121.txt> Acesso em 13 jan. 2014.

Garcia L.S., Bruckner D.A., Brewer T.C. \& Shimizu R.Y. 1983. Techniques for the recovery and identification of Cryptosporidium oocysts from stool specimens. J. Clin. Microbiol. 18:185-190.

Geurden T., Thomas P., Casaert S., Vercruysse J. \& Claerebout E. 2008. Prevalence and molecular characterization of Cryptosporidium and Giardia in lambs and goat kids in Belgium. Vet. Parasitol. 155:142-145.

Goma F.Y., Geurden T., Siwila J., Phiri I.G.K., Gabriel S., Claerebout E. \& Vercruysse J. 2007. The prevalence and molecular characterization of Cryptosporidium spp. in small ruminants in Zambia. Small Rum. Res. 72:77-80.

Henriksen S.A. \& Pohlenz J.F.L. 1981. Staining of cryptosporidia by a modified Ziehl-Neelsen technique. Acta Vet. Scan. 22:594-596.

IBGE. 2014. Efetivo de rebanho por tipo de rebanho. Disponível em $<$ http://www.sidra.ibge.gov.br/bda/tabela/protabl.asp?c=281\&z $=\mathrm{t} \& 0=24 \& \mathrm{i}=\mathrm{P}>$ Acesso em 1 jan. 2014.

Johnson J.K., Schmidt J., Gelberg H.B. \& Kuhlenschmidt M.S. 2004. Microbial adhesion of Cryptosporidium parvum sporozoites: purification of an inhibitory lipid from bovine mucosa. J. Parasitol. 90:980-990.

Majewska A.C., Werner A., Sulima P. \& Luty T. 2000. Prevalence of Cryptosporidium in sheep and goats bred on five farms in west-central region of Poland. Vet. Parasitol.89:269-275.

Mason R.W., Hartley W.J. \& Tilt L. 1981. Intestinal cryptosporidiosis in a kid goat. J. Aust. Vet. Assoc. 57:386-388.

Moss D.M., Montgomery J.M., Newland S.V., Priest J.W. \& Lammie P.J. 2004. Detection of Cryptosporidium antibodies in sera and oral fluids using multiplex bead assay. J. Parasitol. 90:397-404.

Noordeen F., Faizal A.C.M., Rajapakse R.P.V.J., Horadagoda N.U. \& Arulkanthan A. 2001. Excretion of Cryptosporidium oocysts by goats in relation to age and season in the dry zone of Sri Lanka. Vet. Parasitol. 99:79-85.

Noordeen F., Horadagoda N.U., Faizal A.C.M., Rajapakse R.P.V.J., Razak M.A.A. \& Arulkanthan A. 2002. Infectivity of Cryptosporidium parvum isolated from asymptomatic adult goats to mice and goats kids. Vet. Parasitol. 103:217-225.

Noordeen F., Rajapakse R.P.V.J., Faizal A.C.M., Horadagoda N.U. \& Arulkanthan A. 2000. Prevalence of Cryptosporidium infection in goats in selected locations in three agroclimatic zones of Sri Lanka. Vet. Parasitol. 93:95-101.

Pam V.A., Dakul D.A., Karshima N.S., Bata S.I., Ogbu K.I., Daniel L.N., Udokaninyene A.D., Kemza S.Y., Igeh C.P. \& Hassan A.A. 2013. Survey of Cryptosporidium species among ruminants in Jos, Plateau State, NorthCentral Nigeria. J. Vet. Adv. 3:49-54.

Paraud C. \& Chartier C. 2012. Cryptosporidiosis in small ruminants. Small Rum. Res. 103:93-97.
Pavlovic I., Ivanovic S., Žujovic M. \& Tomic Z. 2010. Goat cryptosporidiosis and its importance at goat production pathology. Biotec. Anim. Husbandry 26:187-192.

Robertson L.J. 2009. Giardia and Cryptosporidium infections in sheep and goats: a review of the potential for transmission to humans via environmental contamination. Epidemiol. Infect. 137:913-921.

Santín M. 2013. Clinical and subclinical infections with Cryptosporidium in animals. N. Z. Vet. J. 61:1-10.

Sas Institute. 1996. User's Guide, version 6.11. Vol.2. SAS Institute Inc., Cary. 842p.

Silva M.B.O., Lima J.D., Vieira L.S. \& Vitor R.W.A. 1999. Experimental cryptosporidiosis by Cryptosporidium parvum in dairy goats kids. Revue Méd. Vét. 150:827-830.

Soltane R., Guyot K., Dei-Cas E. \& Ayadi A. 2007. Prevalence of Cryptosporidium spp. (Eucoccidiorida: Cryptosporiidae) in seven species of farm animals of Tunisia. Parasite. 14:335-338.

Teixeira W.F.P., Coelho W.M.D., Soutello R.V.G., Oliveira F.P., Homem C.G., Nunes C.M. \& Meireles M.V. 2011. Diagnóstico de criptosporidiose em amostras fecais de bezerros por imunofluorescência direta e microscopia de contraste de fase. Ciência Rural 41:1057-1062.

Tembue A.A.M., Alves L.C., Borges J.C.G., Faustino M.A.G. \& Machado E.L.C. 2006. Ocorrência de Cryptosporidium spp. em ovinos no município de Ibimirim, Estado de Pernambuco. Ciênc. Vet. Tróp. 9:41-43.

Tyzzer E.E. 1907. A sporozoan found in the peptic glands of the common mouse. Exp. Biol. Med. 5:12-13.

Tzipori S. \& Griffths J.K. 1998. Natural history and biology of Cryptosporidium parvum. Adv. Parasitol. 40:4-36.

Venturini L., Bacigalupe D., Basso W., Unzaga J.M., Venturini M.C. \& Moré G. 2006. Cryptosporidium parvum em animales domésticos y em monos de un zoológico. Parasitol. Latinoam. 61:90-93.

Vieira L.S., Silva M.B.O., Tolentino A.C.V., Lima J.D. \& Silva A.C. 1997. Outbreak of cryptosporidiosis in dairy goats in Brazil. Vet. Rec. 140:427428.

Xiao L., Fayer R., Ryan U. \& Upton S.J. 2004. Cryptosporidium taxonomy: recent advances and implications for public health. Clin. Microbiol. Rev. 17:72-97.

Xiao L., Limor J., Morgan U.M., Sulaiman I.M., Thompson R.C. \& Lal A.A. 2000. Sequence differences in the diagnostic target region of the oocyst wall protein gene of Cryptosporidium parasites. Appl. Environ. Microbiol. 66:5499-5502.

Zar J.H. 1999. Biostatistical Analysis. Prentice Hall, Upper Saddle River. 930p.

Zimmerman S.K.I. \& Needham C.A. 1995. Comparison of conventional stool concentration and preserved-smear methods with Merifluor Cryptosporidium/Giardia Direct Immunofluorescence Assay and ProSpecT Giardia EZ Microplate Assay for detection of Giardia lamblia. J. Clin. Microbiol. 33:1942-1943.

Zorana M., Sofija K. \& Sadrižaj K.Z. 2006. Cryptosporidium infection in lambs and goats kids in Serbia. Acta Vet., Beograd, 56:49-54. 